\title{
The Role of Surgical Resection as A Salvage Therapy and Immunohistochemical Stain to Confirm Mediastinal Yolk Sac Tumor
}

\author{
Dwi Rosa Eka Agustina ${ }^{1}$, Suryanti Dwi Pratiwi ${ }^{1}$, Diah Prabawati Retnani ${ }^{2}$, Artono Isharanto ${ }^{3}$, \\ Rachma Dini Erawati ${ }^{4}$
}

\begin{abstract}
Pulmonology and Respiratory Department, Saiful Anwar Hospital, Universitas Brawijaya, Jaksa Agung Suprapto 2, Malang, 65112, Indonesia Pathology Anatomy Department, Saiful Anwar Hospital, Universitas Brawijaya, Jaksa Agung Suprapto 2, Malang, 65112, Indonesia Thoracic and Cardiovascular Surgery Department, Saiful Anwar Hospital, Universitas Brawijaya, Jaksa Agung Suprapto 2, Malang, 65112, Indonesia Radiology Department, Saiful Anwar Hospital, Universitas Brawijaya, Jaksa Agung Suprapto 2, Malang, 65112, Indonesia

\section{Abstract}

Background: Mediastinal germ cell tumors are uncommon, representing less than $1 \%$ of all malignancies. They mostly occur in young men after puberty and have a poor prognosis with over all long term survival rate $42 \%$.

Case Report: We reported a case report in Saiful Anwar Malang Hospital, Indonesia, a young man, 26 years old with an anterior mediastinum tumor and VCSS The CT scan of the chest showed an anterosuperior mediastinal mass which compress the superior vena cava. The result from transthoracic FNAB with USG guidance showed an extragonadal germ cell tumor which resemble an Embryonal Carcinoma from mediastinum. The AFP serum level was elevated. Patient underwent a radiotherapy and a surgical debulking. The biopsy showed an Endodermal Sinus Tumor (Yolk Sac). Immunohistochemical stain for cytokeratin was positive in the tumor cells while stain for CD30 was negative. These were confirming the diagnosis of primary mediastinal yolk sac tumor. Patient received a combination chemotherapy for a total 6 cycles. Conclusion: Some procedures like biopsy, tumor marker, immunohistochemical stain, could differentiate the subtype of mediastinal germ cell tumor. The multimodality treatment by combining chemotherapy with surgical therapy or radiotherapy could increase the survival outcome of patients.

MRJ 2019; 1(1):49-55

Keywords: debulking, salvage therapy, immunohistochemical stain, yolk sac tumor

\section{Introduction}

Germ cell mediastinal tumors are rare neoplasms that account for less than $1 \%$ of all malignancies, and $3-4 \%$ of all germ cell tumors occur in both adults and children. The annual incidence of germ cell mediastinal tumors differs in caucasian races $\sim 10$ / 100,000; while African and Asian races are 1-2 / 100,000. ${ }^{1,2}$ Classification of germ cell mediastinal tumor is similar to those in the gonadal tumor such as: Teratoma, Seminoma, Non-Seminoma that consist *Corresponding author: Dwi Rosa Eka Agustina (dwi.rosa.eka.agustina@gmail.com) Pulmonology and Respiratory Department, Saiful Anwar Hospital - Universitas Brawijaya, Jaksa Agung Suprapto St. No. 2, Malang. 65112, Indonesia

mrj.ub.ac.id|

Vol 01 (1) page 49

of yolk sac tumors, embryonal carcinomas, choriocarcinomas and mixed germ cell tumors. ${ }^{3,4}$ The average occurrence of patients aged 15-59 years is 0.3 cases per 1 million individuals per year. Pure Yolk tumors are the fourth most common cause of germ cell tumors following teratomas, seminomas and mixed germ cell tumors in adolescents and adults. ${ }^{5}$ The clinical symptoms of mediastinal germ cell tumors are shortness of breath $(25 \%)$, chest pain $(23 \%)$, cough $(17 \%)$, fever $(13 \%)$, night 
sweat or weight loss (11\%). Night sweat, fatigue, hemoptysis and compression of the vena cava superior occurred in less than $10 \%$ in the mediastinal germ cell tumors. ${ }^{1,6}$ The thoracic CT scan showed an inhomogeneous bulky mediastinal mass with hemorrhage and necrotic in multiple area. ${ }^{7,8}$ In $90 \%$ of patients with non-seminoma germ cell tumors, high levels of b-hCG (30\%-50\% of patients) or AFP (80\% of patients) can occur. An increase in AFP of more than $500 \mathrm{ng} / \mathrm{ml}$ for non-seminoma germ cell tumors is essential for diagnosis. ${ }^{8}$ Histological finding in the yolk sac tumor is the Schiller-Duval bodies. ${ }^{1,4,6}$ The management of yolk sac tumor is neoadjuvant chemotherapy followed with tumor resection from the residual tumor. If the pathology showed tumor cells, it will be added an adjuvant chemotherapy. Because of the rarity of the tumor and difficulty of establishing the diagnosis, the tumor resection is one of the primary modality and therapy that will be followed with chemotherapy. ${ }^{9}$ Patient with non-seminoma germ cell tumor had a poor prognosis, but the platinum-based chemotherapy showed significant improvement. In some research, patient that was treated with platinum-based chemotherapy as first line showed $42 \%$ long term survival rate. After completed chemotherapy, restaging with thoracic and abdominal CT scan and tumor marker should be done. $^{8}$

\section{Background}

This case report was published because of the rarity of the mediastinal yolk sac tumor with the VCSS as the complication. The multimodality diagnostic procedure and therapy need to be discussed with the multidiscipline team (MDT) to get the most suitable treatment for each patient.

\section{Case}

Patient is male, 26 years old with chief complain shortness of breath for 1 month, history of hemoptysis $15-30 \mathrm{cc}$, right chest pain, fever in the last 5 days and decreased of body weight $4 \mathrm{~kg}$ in a month. He also felt swelling in his neck and right arms in the last 10 days. There was history of ORIF surgery in his left arm in 2015 and no history of previous respiratory symptoms that was proved by normal Chest X-Ray in 2015. He was a labor in the gasoline station and he smoked cigarette occasionally, 1-3 cigarette per day for 12 years and already stopped smoking. From the 
physical examination there were (431.000/ $\mu \mathrm{L})$, AFP level was elevated to tachycardia (heart rate 120/ $\mathrm{min}$ ), $23.248 \mathrm{ng} / \mathrm{mL}$ (normal range 0 prominent superficial vascularity of $20 \mathrm{ng} / \mathrm{mL}$ ), increased of LDH level 1147 upper chest and abdomen, gynecomastia, decreased of stem fremitus in the upper and middle right chest, dullness in the upper and middle right chest, and decreased of the breath sound in the upper and middle right chest, and slightly swelling in his right arm. Thoracic CT scan with contrast in 2017 showed in Fig 1. The laboratory result showed leukocytosis $(37.990 / \mu \mathrm{L})$, slightly increased of platelets

$\mathrm{U} / \mathrm{L}$ and $\beta-\mathrm{HCG}$ level within normal limit $(1,01 \mathrm{mIU} / \mathrm{mL})$. The bronchoscopy showed an extraluminal stenosis from one third distal trachea to the superior lobe right bronchus and truncus intermedius. The cytology from transthoracic needle aspiration (TTNA) with ultrasound guiding showed a malignant germ cell tumor that resemble an embryonal carcinoma from mediastinum (fig 2).

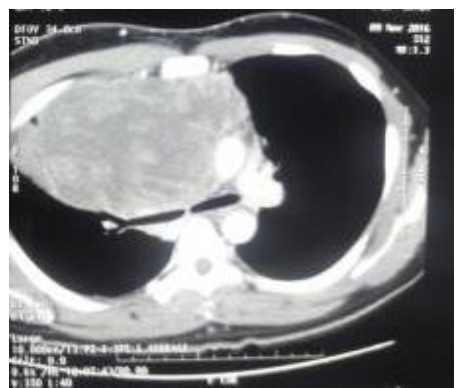

Axial

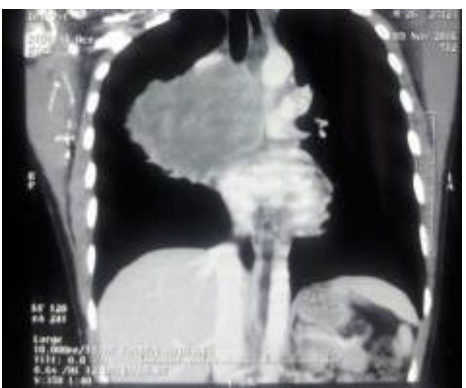

Coronal

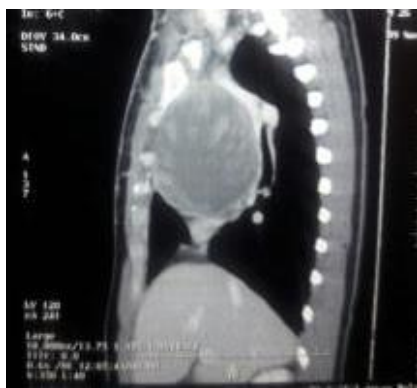

Sagital

Figure 1. Heterogenous mediastinal mass in right anterosuperior, attached and suppressed the aortic, brachiocephalic vein, superior vena cava, and attached to the anterior thoracic wall.

We initial diagnosed this patient with mediastinal germ cell tumor with VCSS, patient underwent radiotherapy and surgical debulking for salvage therapy for the VCSS then chemotherapy adjuvant for the tumour. We examined the histology of the tumour and the immuno-histochemical stain. The histopathology result from post-surgical debulking showed Schiler-Duval Bodies 
(fig 2) and the immuno-histochemical

stain showed positive cytokeratin (fig 2).

The Radiology evaluation after surgical

debulking and chemotherapy were

evaluated and showed in fig 3. Patient was also given adjuvant chemotherapy

with Carboplatin and Etoposide 6 cycles

and there were decreased of AFP level in

the evaluation as shown in the table 1

Table 1. Tumor Marker evaluation in the 6 cycle of EP chemotherapy

\begin{tabular}{|l|l|l|l|l|l|l|}
\hline $\begin{array}{l}\text { Tumor } \\
\text { marker }\end{array}$ & I & II & III & IV & V & VI \\
\hline AFP & 23.248 & - & 5791 & 4246 & 7036 & - \\
\hline beta hCG & 1,01 & - & 0,35 & 0,10 & 0,52 & 1,35 \\
\hline LDH & 1147 & 824 & 975 & 862 & 1189 & 1409 \\
\hline
\end{tabular}
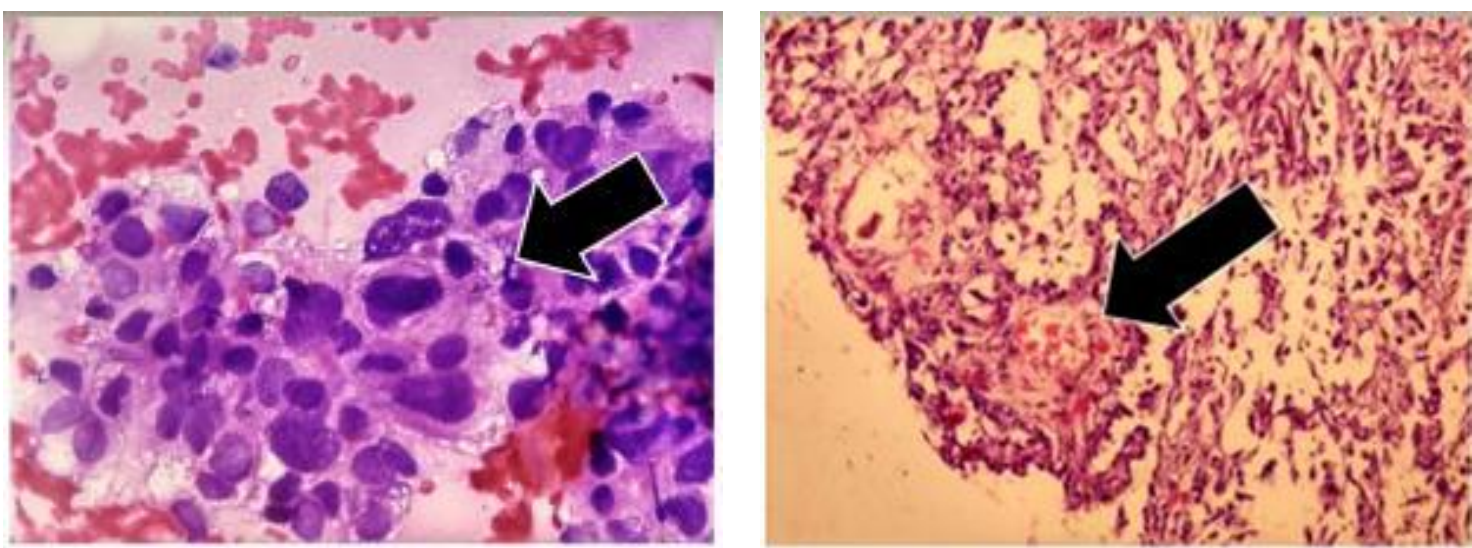

A

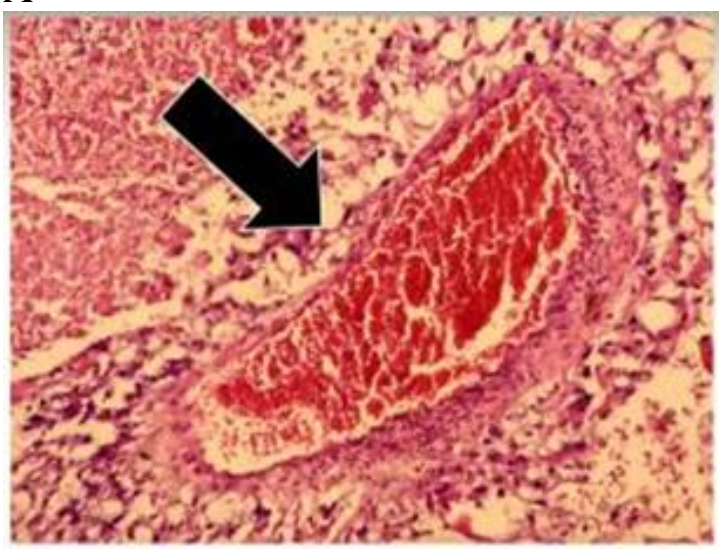

B

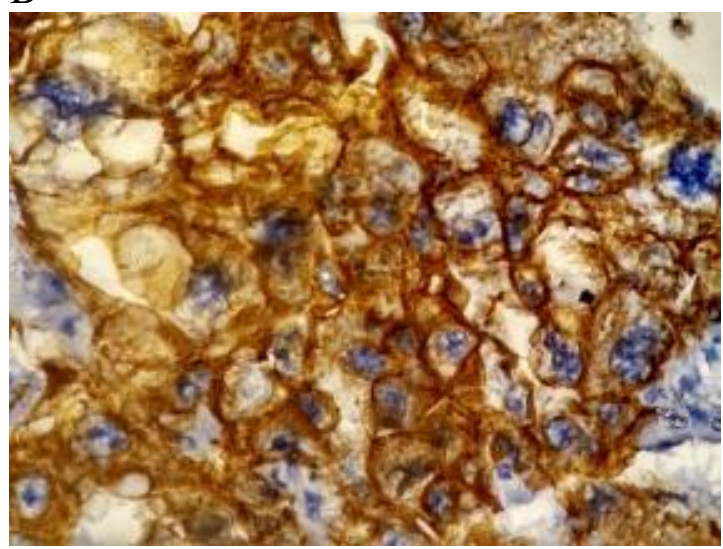

$\mathrm{D}$

$\mathrm{C}$

Figure 2. Cytology Result Showed Large Cell Tumour, Pleomorphism, Hyperchromatic and Prominent Nucleoli (A). Schiler-Duval Bodies (B\&C) and the immunohistochemical stain showed positive cytokeratin 


\section{Discussion}

Mediastinal Yolk sac tumor is one of the sub-type of germ cell tumor, mostly occurred in young men after puberty and have a poor prognosis. VCSS occurred in $3 \%$ of germ cell tumor patient. Although the earliest cytology result showed an mediastinal germ cell tumor that resemble an embryonal carcinoma from mediastinum, the biopsy confirmed a mediastinal yolk sac tumor because it showed a Schiller-Duval bodies. It will be shown in $50-75 \%$ in yolk sac tumor. ${ }^{1,8}$ Tumor markers (AFP \& B-hCG) could establish either seminoma or nonseminoma germ cell tumor, and have prognostic value. AFP Serum $>10,000$ $\mathrm{ng} / \mathrm{ml}$ and mediastinal primary tumor have a poor prognosis. ${ }^{8,10}$
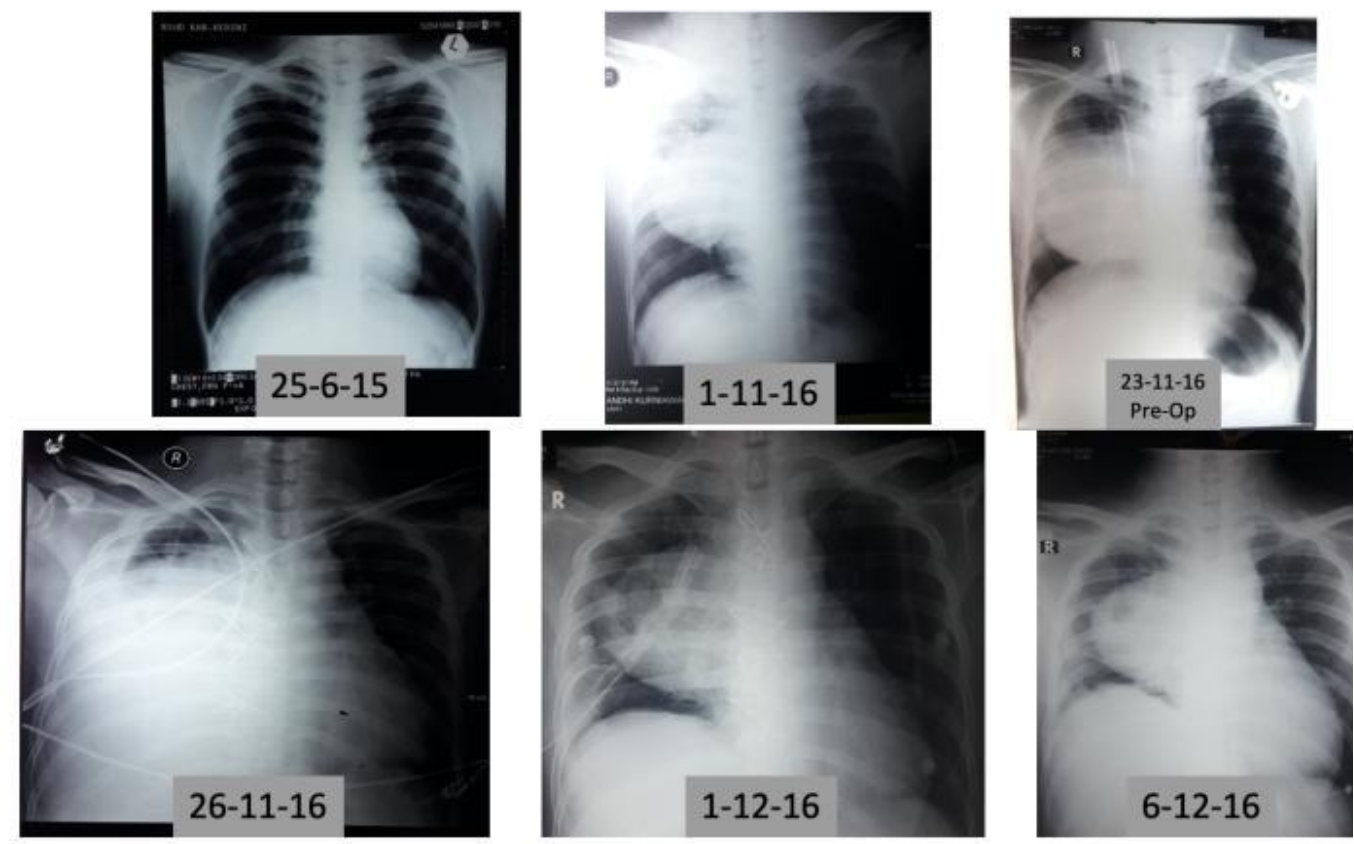

Figure 3. The Evaluation of the Chest X-Rays after surgical debulking

The treatment of choice for yolk sac tumor is chemotherapy. But in this case we perform initial radiotherapy for the
VCSS although the characteristic of this tumor is radio-resistant. Surgical debulking in this patient as a "salvage 
surgery" which is intended to reduce chemotherapy resistant disease, reduce the tumor burden that cause VCSS and asses the pathology of tumor. Six cycles chemotherapy with Etoposide \& Carboplatin can reduce AFP level from 23.248 to $7.036 \mathrm{ng} / \mathrm{ml}$ and reduce the mass volume. In this case, patient achieved 7\% mass reduction from 3rd cycle of chemotherapy. Some studies demonstrated that chemotherapy combined with surgery or radiotherapy resulted in the longest survival time, compared with monotherapy. In most series, patients treated with initial chemotherapy followed by surgery had a superior outcome to those treated with initial surgery. ${ }^{11,12,13}$ with mediastinal yolk sac tumors carry a poor prognosis and have a lower likelihood of achieving a complete response to combined modality therapy. ${ }^{11}$

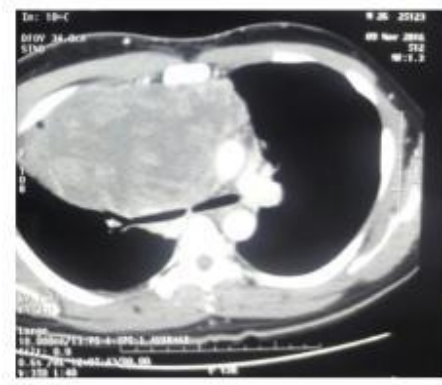

November $9^{\text {th }}, 2016$

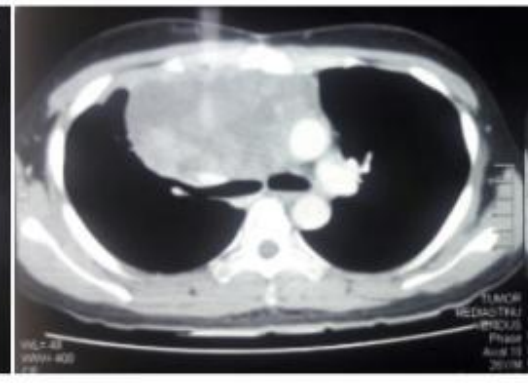

March $20^{\text {th }}, 2017$

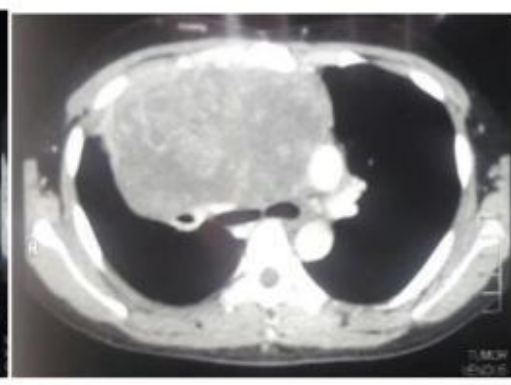

May $23^{\text {th }}, 2017$

Figure 4. The Evaluation of The Thoracic CT Scan after Chemotherapy showed a stable disease

\section{Summary}

This patient was confirmed to have primary mediastinal yolk sac tumor with

VCSS by clinical symptoms, thoracic

CT-scan, tumor marker, histopathology, and immunohistochemical stain.
Diagnostic procedure and treatment strategies for mediastinal yolk sac tumor are important because of the rarity of this tumor. The initial therapy, whether surgical or chemotherapy, is influenced by many factors, such as patient status, 
tumor size and invasion, skill and

experience of the oncology center.

\section{References}

1. Travis WD. Pathology \& genetics tumours of the lung, pleura, thymus and heart. World Health Organization classification of tumours. 2004.

2. Papaioannou ${ }^{1}$ A, Porpodis K, Spyratos $\mathrm{D}$, Zarogoulidis K. Yolk sac tumour in the anterior mediastinum. www. pneumon. org. 2013 Oct;1(4):359.

3. McKenney JK, Heerema-McKenney A, Rouse RV. Extragonadal germ cell tumors: a review with emphasis on pathologic features, clinical prognostic variables, and differential diagnostic considerations. Advances in anatomic pathology. 2007 Mar 1;14(2):69-92.

4. DeVita VT, Lawrence TS, Rosenberg SA, editors. DeVita, Hellman, and Rosenberg's cancer: principles \& practice of oncology. Lippincott Williams \& Wilkins; 2015.

5. Travis WD, Brambilla E, Burke AP, Marx A, Nicholson AG. Introduction to the 2015 World Health Organization classification of tumors of the lung, pleura, thymus, and heart. Journal of Thoracic Oncology. 2015 Sep 1;10(9):1240-2.

6. Nakhla SG, Sundararajan S. A rare case of primary anterior mediastinal yolk sac tumor in an elderly adult male. Case reports in oncological medicine. 2016;2016.

7. Hainsworth JD, Greco FA. Malignant Germ Cell Tumors. In: Kufe DW, Pollock RE, Weichselbaum RR, et al., editors. Holland-Frei Cancer Medicine. 6th edition. Hamilton (ON): BC Decker; 2003.

8. Grippi MA, Elias JA, Fishman JA, Pack AI, Senior RM, Kotloff R. Fishman's Pulmonary Diseases and Disorders, 2Volume Set. McGraw Hill Professional; 2015 Apr 17.
9. Rahman AR, Ebied EN, Nouh MA, Gal AA, Mansour KA. Primary yolk sac tumor of the lung. The Annals of thoracic surgery. 2009 Jun 1;87(6):1925-6.

10. Steele GS, Richie JP, Oh WK, Michaelson D. Clinical manifestations, diagnosis, and staging of testicular germ cell tumors. UpToDate. Kantoff PW (Ed). UpToDate. Waltham MA. 2015 Jan.

11. Liu TZ, Zhang DS, Liang Y, Zhou NN, Gao HF, Liu KJ, Wu HY. Treatment strategies and prognostic factors of patients with primary germ cell tumors in the mediastinum. Journal of cancer research and clinical oncology. 2011 Nov 1;137(11):1607.

12. Sakaguchi M, Maebayashi T, Aizawa T, Ishibashi N, Fukushima S, Saito T. Successful radiotherapy in postoperative recurrence of a primary mediastinal yolk sac tumor: A case report. Thoracic cancer. 2016 May;7(3):358-62.

13. Motzer RJ, Jonasch E, Agarwal N, Beard C, Bhayani S, Bolger GB, Chang SS, Choueiri TK, Costello BA, Derweesh IH, Gupta S. Testicular cancer, version 2.2015. Journal of the National Comprehensive Cancer Network. 2015 Jun 1;13(6):772-99. 